\title{
Lola Bermùdez, Une machine textuelle, Faustroll
}

\section{Erica Tacchino}

\section{(2) OpenEdition}

\section{Journals}

\section{Edizione digitale}

URL: https://journals.openedition.org/studifrancesi/46174

DOI: 10.4000/studifrancesi.46174

ISSN: 2421-5856

\section{Editore}

Rosenberg \& Sellier

\section{Edizione cartacea}

Data di pubblicazione: 1 octobre 2007

Paginazione: 471

ISSN: 0039-2944

\section{Notizia bibliografica digitale}

Erica Tacchino, «Lola Bermùdez, Une machine textuelle, Faustrol/», Studi Francesi [Online], 152 (LI | II) |

2007, online dal 30 novembre 2015, consultato il 24 novembre 2021. URL: http://

journals.openedition.org/studifrancesi/46174 ; DOI: https://doi.org/10.4000/studifrancesi.46174

Questo documento è stato generato automaticamente il 24 novembre 2021.

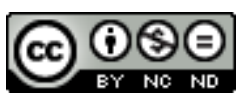

Studi Francesi è distribuita con Licenza Creative Commons Attribuzione - Non commerciale - Non opere derivate 4.0 Internazionale. 


\title{
Lola Bermùdez, Une machine textuelle, Faustroll
}

\author{
Erica Tacchino
}

\section{NOTIZIA}

LOLA BERMÙDEZ, Une machine textuelle, Faustroll, «Revue des Sciences Humaines», L'imaginaire de l'électricité, janvier 2006, n. 281, pp. 163-177.

1 Gestes et opinions du Docteur Faustroll, pataphysicien, che Alfred Jarry scrive tra il 1897 ed il 1898, ma che viene pubblicato quattro anni dopo la sua morte, segna una svolta intorno al modello di romanzo scientifico, non più rivolto a testimoniare la realtà, ma a sostenere la cosiddetta meccanica immaginaria.

2 L'articolo di Lola Bermudez si basa sullo studio di questo testo allo scopo di dimostrare l'importanza del linguaggio impiegato da Jarry, sul quale si fonda il romanzo, una machine textuelle per mezzo della quale il poetico e lo scientifico si uniscono per dare vita a trascrizioni del reale attraverso una letteratura basata su una propria interpretazione dell'universo letterario.

3 Da una parte lo scrittore adotta elementi simbolisti però trasformandoli (per esempio l'eternità non è più un concetto trascendente ma diventa immanente, eternità pura, in cui Faustroll continua a collocarsi); dall'altra, essendo il simbolismo anti-scientifico, si comprende come l'uso della scienza si ponga qui a favore della poetica del testo, poiché le scoperte scientifiche rappresentano un elemento immaginario.

4 È attraverso la "patafisica" che si attua quest'operazione: la scienza delle soluzioni immaginarie, che accorda simbolicamente ai lineamenti di una dottrina le proprietà degli oggetti descritti nella loro virtualità. Infatti, non esistono più le coordinate spazio-temporali, lo spazio è virtuale e non si segue alcun ordine cronologico. 
5 La studiosa nota come "l'elettricità" s'intraveda all'interno del testo: elementi come etere, raggi infrarossi, i fisici dell'epoca menzionati, e termini come "condensatore" e "generatore" sottolineano la nascita di questa nuova forma di energia. 